\title{
KETAHANAN BEBERAPA GENOTIPE JAGUNG (ZEA MAYS) INTRODUKSI TERHADAP SERANGAN HAMA
}

\author{
Dewi Rumbaina Mustikawati ${ }^{1}$ dan Andarias Makka Murni ${ }^{1}$
}

\begin{abstract}
The resistance of some introduced hybrid genotypes maize (Zea mays) towards insect pests. Plant resistance to insect pest play an important role in integrated pest management. Fourty hybrid genotypes released by CIMMYT Mexico and two National hybrid varieties (Pioner 13 and Andalas) as local control had been tested their resistance to insect pests. The trial was conducted at Natar Station Experimental, South Lampung from April to July 2002. The objective of the experiment was to obtaine the hybrid genotypes in which have a good tolerant or resistance toward insect pests. Alpha latice design with three replicates were used in this experiment. The varieties were grown in two-row plots of $5 \mathrm{~m}$ length at row-to-row spacing of $75 \mathrm{~cm}$ and hill-to-hill spacing within rows of $25 \mathrm{~cm} .300 \mathrm{~kg}$ Urea, $150 \mathrm{~kg}$ SP-36 and $100 \mathrm{~kg} \mathrm{KCl} \mathrm{ha-}{ }^{-1}$ was applied to the trial. Insect pests damage were observed at 16 and 80 days after planting. The results showed that there were 12 genotypes have moderate resistance toward insect pests : CMS 991006, CMT 011004, CMT 011018, CMT 011028, CMT 011030, CMT 011036, CMT 011038, CMT 011044, CMT 011050, CMS 951220 (RE), CMT 011056, CMT 011060 and one genotype was susceptible that was CMS 991018, however the others showed varies resistance traits against insect
pest.
\end{abstract}

Kata kunci: jagung, genotipe, ketahanan terhadap hama

\section{PENDAHULUAN}

Produktivitas jagung nasional masih rendah, rata-rata 2,8 ton/ha (Balai Penenelitian Tanaman Serelia, 2002). Rendahnya hasil tersebut berkaitan dengan berbagai kendala yang dihadapi dalam usahatani jagung, salah satunya adalah adanya serangan hama penyakit serta penggunaan varietas yang berdaya hasil rendah.

Badan Litbang Pertanian telah melepas beberapa varietas unggul baik bersari bebas maupun hibrida. Keberhasilan Badan Litbang Pertanian merakit varietas unggul jagung tidak terlepas dari kegiatan pengembangan dan pelestarian plasma nutfah. Sumber daya genetik yang digunakan berasal dari koleksi varietas local dan introduksi (Balai Penenelitian Tanaman Serelia, 2002). Sejumlah varietas unggul yang dilepas, berumur genjah, tahan penyakit bulai, daya adaptasi lebih luas dan hasil tinggi. Plasma nutfah jagung nasional diperkaya oleh sumber daya genetik introduksi hasil kerjasama Badan Litbang Pertanian dengan Pusat Penelitian Jagung Internasional (CIMMYT). Sebagian besar varietas unggul yang dilepas memiliki sifat yang diwariskan oleh bahan genetik introduksi.
Sampai saat ini varietas jagung unggul yang dilaporkan adalah tahan terhadap penyakit bulai dengan reaksi ketahanan agak tahan sampai tahan, sedangkan jagung varietas Kalingga dan Lamuru dinyatakan tahan terhadap serangan hama kumbang bubuk (Balai Penenelitian Tanaman. Serelia, 2002). Varietas tahan hama memiliki peranan penting dalam Pengendalian Hama Terpadu (PHT), karena tidak hanya mudah diadopsi petani tetapi secara ekonomis juga dapat mengurangi biaya pengendalian. Varietas tahan hama sifatnya kumulatif, aditif, kompatibel dengan komponen PHT lainnya, dan tidak menimbulkan pencemaran lingkungan (Prasadja dkk., 1993).

Pada penelitian ini beberapa genotipe jagung hibrida yang telah dirakit di CIMMYT Mexico diuji daya adaptasinya terhadap kondisi agroekosistem Lampung. Tujuan dari penelitian ini adalah mengetahui reaksi ketahanan dari genotipe-genotipe tersebut terhadap serangan hama.

\section{METODE PENELITIAN}

Penelitian dilakukan di Kebun Percobaan Natar, Lampung Selatan dari bulan April-Juli 2002. Jagung hibrida yang diuji berjumlah 40 genotipe

\footnotetext{
Balai Pengkajian Teknologi Pertanian Lampung, J. Zainal Abidin Pagaralam, Bandar Lampung
} 
Tabel 1. Jenis genotipe jagung yang diuji ketahanannya terhadap serangan hama

\begin{tabular}{|l|l|l|}
\hline 1. CMS 991002 & 15. CMT 011022 & 29. CMT 011046 \\
2. CMT 011002 & 16. CMT 011024 & 30. CMT 011048 \\
3. CMS 991006 & 17. CMS 97111010 & 31. CMT 011050 \\
4. CMT 011004 & 18. CMT 011026 & 32. CMS 951220 (RE) \\
5. CMT 011006 & 19. CMT 011028 & 33. CMT 011052 \\
6. CMS 991012 & 20. CMT 011030 & 34. CMT 011054 \\
7. CMT 011008 & 21. CMS 981016 & 35. CMT 011056 \\
8. CMT 011010 & 22. CMT 011022 & 36. CMT 011058 \\
9. CMT 011012 & 23. CMT 011034 & 37. CMS 9510204 \\
10. CMT 011014 & 24. CMT 011036 & 38. CMT 011060 \\
11. CMT 011016 & 25. CMT 011038 & 39. CMT 011062 \\
12. CMT 011018 & 26. CMT 011040 & 40. CMS 971006 \\
13. CMS 991018 & 27. CMT 011042 & 41. Local check-1 (Var. Pioneer 13) \\
14. CMT 011020 & 28. CMT 011044 & 42. Local check-2 (Var. Andalas) \\
\hline
\end{tabular}

introduksi berasal dari CIMMYT Meksiko, dan 2 varietas pembanding (Tabel 1). Percobaan menggunakan rancangan Alpha latice terdiri atas tiga ulangan. Setiap plot terdiri atas dua baris tanaman, dengan panjang baris $5 \mathrm{~m}$. Jarak tanam $75 \mathrm{~cm}$ antar baris dan $25 \mathrm{~cm}$ dalam baris. Tanaman dipupuk 300 $\mathrm{kg}$ Urea, $150 \mathrm{~kg}$ SP-36 dan $100 \mathrm{~kg} \mathrm{KCl} / \mathrm{ha}$. Pengamatan hama dilakukan pada saat tanaman berumur 16 hari dan 80 hari. Persentase serangan dihitung dengan rumus :

$P=\frac{a}{a+b} \times 100 \%$

Keterangan:

$\mathrm{P}=$ persentase serangan $(\%) ; \mathrm{a}=$ jumlah tanaman terserang; $b=$ jumlah tanaman tidak terserang.

Untuk melihat reaksi ketahanan genotipe terhadap serangan hama digunakan metode Chiang dan Talekar (1980), yaitu (a) sangat tahan : $<X-2$ SD; (b) tahan : X - 2 SD s/d X - 1 SD; (c) agak tahan : X - 1 SD s/d X; (d) peka : X s/d X + 1 SD; (e) sangat peka : $>X+1$ SD. $X=$ rata-rata, $S D=$ standar deviasi.

\section{HASIL DAN PEMBAHASAN}

Hasil pengamatan menunjukkan bahwa saat tanaman berumur 16 hari ada tiga jenis hama yang menyerang pertanaman jagung yaitu hama perusak daun Spodoptera sp., Mythimna sp., dan Elasmopalpus lignocellus. Ulat Spodoptera sp. yang baru menetas memakan epidermis daun, ulat Mythimna sp. memakan daun, sedangkan Elasmopalpus lignocellus merusak daun pucuk yang menyebabkan daun pucuk seperti menggulung. Saat tanaman berumur 80 hari hanya satu jenis hama yang menyerang pertanaman yaitu penggerek batang Ostrinia sp.

Reaksi ketahanan genotipe-genotipe jagung yang diuji terhadap serangan hama-hama tersebut dapat dilihat pada Tabel 2. Pada umumnya, masingmasing genotipe menunjukkan ketahanan yang beragam, seperti genotipe CMS 991002 (No. 1), terserang Spodoptera sp. 8,72 \%, angka ini terletak diantara $(X-1 S D)=-20,58$ dan $(X)=8,92$, sesuai metoda Chiang dan Talekar (1980) sehingga disimpulkan agak tahan. Seterusnya genotipe CMS 991002 ini terserang Mythima sp. 2,38 \%, angka ini terletak diantara $(X-1 S D)=0,09$ dan $(X)=7,35$, 
Tabel 2. Reaksi ketahanan masing-masing genotipe jagung hibrida terhadap serangan hama

\begin{tabular}{|c|c|c|c|c|c|c|c|c|}
\hline No. Kode Hibrid & $\begin{array}{c}\text { Serangan } \\
\text { Spodoptera sp. } \\
(\%) \\
\text { (Tanaman umur } \\
16 \mathrm{hr})\end{array}$ & $\begin{array}{c}\text { Reaksi } \\
\text { ketahanan }\end{array}$ & $\begin{array}{c}\text { Serangan } \\
\text { Mythimma sp. } \\
(\%) \\
\text { (Tanaman } \\
\text { umur } 16 \mathrm{hr})\end{array}$ & $\begin{array}{c}\text { Reaksi } \\
\text { ketahanan }\end{array}$ & $\begin{array}{c}\text { Serangan } \\
\text { Elasmopalpus } \\
\text { lignocellus } \\
(\%) \text { (Tanaman } \\
\text { umur } 16 \mathrm{hr})\end{array}$ & $\begin{array}{c}\text { Reaksi } \\
\text { ketahanan }\end{array}$ & $\begin{array}{c}\text { Serangan } \\
\text { Ostrinia sp. } \\
(\%) \\
\text { (Tanaman } \\
\text { umur } \\
80 \mathrm{hr} \text { ) }\end{array}$ & $\begin{array}{c}\text { Reaksi } \\
\text { ketahanan }\end{array}$ \\
\hline 1. CMS 991002 & 8,72 & AT & 2,38 & AT & 0,93 & P & 0,79 & AT \\
\hline 2. CMT 011002 & 1,59 & AT & 0,79 & AT & 0,26 & AT & 3,17 & $\mathrm{P}$ \\
\hline 3. CMS 991006 & 4,76 & AT & 0,79 & AT & 0,00 & AT & 0,79 & AT \\
\hline 4. CMT 011004 & 5,55 & AT & 3,17 & AT & 0,79 & AT & 0,00 & AT \\
\hline 5. CMT 011006 & 3,97 & AT & 2,38 & AT & 0,00 & AT & 2,38 & $\mathrm{P}$ \\
\hline 6. CMS 991012 & 3,97 & AT & 3,97 & $\mathrm{P}$ & 0,79 & AT & 0,00 & AT \\
\hline 7. CMT 011008 & 1,59 & AT & 4,76 & $\mathrm{P}$ & 0,79 & AT & 2,38 & $\mathrm{P}$ \\
\hline 8. СMT 011010 & 3,17 & AT & 4,76 & $\mathrm{P}$ & 0,79 & AT & 0,00 & AT \\
\hline 9. CMT 011012 & 3,97 & AT & 3,97 & $\mathrm{P}$ & 0,79 & AT & 0,00 & AT \\
\hline 10. CMT 011014 & 3,97 & AT & 3,97 & $\mathrm{P}$ & 0,00 & AT & 1,59 & $P$ \\
\hline 11. CMT 011016 & 11,11 & P & 3,17 & AT & 0,00 & AT & 2,38 & $\mathrm{P}$ \\
\hline 12. CMT 011018 & 6,35 & AT & 2,38 & AT & 0,00 & AT & 0,00 & AT \\
\hline 13. CMS 991018 & 10,31 & $\mathrm{P}$ & 7,14 & $\mathrm{P}$ & 7,12 & SP & 1,59 & $\mathbf{P}$ \\
\hline 14. CMT 011020 & 2,38 & AT & 4,76 & P & 0,00 & AT & 0,00 & $\mathrm{AT}$ \\
\hline 15. CMT 011022 & 3,17 & AT & 4,76 & P & 0,00 & AT & 0,79 & AT \\
\hline 16. CMT 011024 & 4,76 & AT & 3,97 & $\mathrm{P}$ & 1,59 & P & 1,59 & $P$ \\
\hline 17. CMS 97111010 & 4,76 & AT & 3,17 & AT & 0,97 & AT & 2,38 & $\mathrm{P}$ \\
\hline 18. CMT 011026 & 3,97 & AT & 6,93 & $\mathrm{P}$ & 1,59 & $\mathrm{P}$ & 0,00 & AT \\
\hline 19. CMT 011028 & 2,38 & AT & 0,79 & AT & 0,00 & AT & 0,00 & AT \\
\hline 20. CMT 011030 & 7,14 & AT & 0,79 & AT & 0,00 & AT & 0,00 & AT \\
\hline 21. CMS 981016 & 3,17 & AT & 3,17 & AT & 1,59 & $P$ & 2,38 & $\mathrm{P}$ \\
\hline 22. CMT 011022 & 7,14 & AT & 3,97 & $\mathrm{P}$ & 0,00 & AT & 0,79 & AT \\
\hline 23. CMT 011034 & 4,76 & AT & 10,31 & $\mathrm{SP}$ & 0.79 & AT & 0,00 & AT \\
\hline 24. CMT 011036 & 3,97 & AT & 1,59 & AT & 0,79 & AT & 0,00 & AT \\
\hline 25. CMT 011038 & 4,76 & AT & 2,38 & AT & 0,79 & AT & 0,00 & AT \\
\hline 26. CMT 011040 & 2,38 & AT & 1.59 & AT & 0,79 & AT & 1,59 & $\mathrm{P}$ \\
\hline 27. CMT 011042 & 7,14 & AT & 6,35 & $\mathrm{P}$ & 1,59 & $\mathrm{P}$ & 2,38 & $\mathrm{P}$ \\
\hline 28. CMT 011044 & 5,55 & AT & 1,59 & AT & 0,00 & AT & 0,00 & AT \\
\hline 29. CMT 011046 & 8,73 & AT & 3,97 & $\mathrm{P}$ & 0,79 & AT & 2,38 & $\mathrm{P}$ \\
\hline 30. CMT 011048 & 10,31 & $\mathrm{P}$ & 5,55 & $P$ & 1,59 & $\mathrm{P}$ & 0,79 & AT \\
\hline 31. CMT 011050 & 1,59 & AT & 0,00 & $\mathbf{T}$ & 0,00 & AT & 0,79 & AT \\
\hline 32. CMS 951220 (RE) & 3,97 & AT & 3,17 & AT & 0,79 & AT & 0,00 & AT \\
\hline 33. CMT 011052 & 7,14 & AT & 1,59 & AT & 1,59 & $\mathrm{P}$ & 0,00 & AT \\
\hline 34. CMT 011054 & 3,97 & AT & 9,52 & SP & 0,79 & AT & 0,00 & AT \\
\hline 35. CMT 011056 & 4,76 & AT & 2,38 & AT & 0,79 & AT & 0,79 & AT \\
\hline 36. CMT 011058 & 3,97 & AT & 3,97 & $\mathrm{P}$ & 0,79 & AT & 2,38 & $\mathrm{P}$ \\
\hline 37. CMS 9510204 & 4,76 & AT & 6,35 & $\mathrm{P}$ & 0,79 & AT & 2,38 & $\mathrm{P}$ \\
\hline 38. CMT 011060 & 4,76 & AT & 1,59 & AT & 0,00 & AT & 0,00 & AT \\
\hline 39. CMT 011062 & 5,55 & AT & 3,17 & AT- & 0,00 & AT & 4,76 & SP \\
\hline 40. CMS 971006 & 4,76 & AT & 2,38 & AT & 1,59 & $\mathrm{P}$ & 0,00 & AT \\
\hline 41. Local check-1 & 8,73 & AT & 2,38 & AT & 0,79 & $\mathrm{AT}$ & 2,38 & $\mathrm{P}$ \\
\hline 42. Local check-2 & 7,93 & AT & 9,52 & SP & 2,38 & $\mathrm{P}$ & 0,00 & AT \\
\hline Rata-rata (X) & 8,92 & & 3,72 & & 0,84 & & 1,04 & \\
\hline Seandar Deviasi (SD) & 29,50 & & 3,63 & & 1,71 & & 2,20 & \\
\hline$x-2 S D$ & $-50,08$ & & $-3,54$ & & $-2,58$ & & $-3,36$ & \\
\hline$X-1 S D$ & $-20,58$ & & 0,09 & & $-0,87$ & & $-1,16$ & \\
\hline$x+1 S D$ & 38,42 & & 7,35 & & 2,55 & & 3,24 & \\
\hline
\end{tabular}

Keterangan : $\mathrm{T}=$ tahan, $\mathrm{AT}=$ agak tahan, $\mathrm{P}=$ peka, $\mathrm{SP}=$ sangat peka. 
Tabel 3. Hasil pipilan kering beberapa genotipe jagung

\begin{tabular}{|c|c|c|c|}
\hline $\begin{array}{c}\text { Nomor } \\
\text { Kode Hibrid }\end{array}$ & Hasil (t/ha) & $\begin{array}{c}\text { Nomor } \\
\text { Kode Hibrid }\end{array}$ & Hasil (t/ha) \\
\hline $\begin{array}{l}\text { 1. CMS } 91002 \\
\text { 2. CMT } 011002 \\
\text { 3. CMS } 991006 \\
\text { 4. CMT } 011004 \\
\text { 5. CMT } 011006 \\
\text { 6. CMS } 991012 \\
\text { 7. CMT } 011008 \\
\text { 8. CMT } 011010 \\
\text { 9. CMT } 011012 \\
\text { 10. CMT } 011014 \\
\text { 11. CMT } 011016 \\
\text { 12. CMT } 011018 \\
\text { 13. CMS } 991018 \\
\text { 14. CMT } 011020 \\
\text { 15. CMT } 011022 \\
\text { 16. CMT } 011024 \\
\text { 17. CMS } 97111010 \\
\text { 18. CMT } 011026 \\
\text { 19. CMT } 011028 \\
\text { 20. CMT } 011030 \\
\text { 21. CMS } 981016\end{array}$ & $\begin{array}{c}6,46 \mathrm{hij} \\
6,33 \mathrm{f}-\mathrm{j} \\
5,70 \mathrm{a}-\mathrm{j} \\
4,96 \mathrm{a}-\mathrm{d} \\
5,68 \mathrm{a}-\mathrm{I} \\
4,78 \mathrm{a} \\
5,47 \mathrm{a}-\mathrm{g} \\
6,08 \mathrm{e}-\mathrm{j} \\
5,94 \mathrm{e}-\mathrm{j} \\
6,04 \mathrm{e}-\mathrm{j} \\
4,97 \mathrm{a}-\mathrm{d} \\
5,50 \mathrm{a}-\mathrm{h} \\
6,05 \mathrm{e}-\mathrm{j} \\
4,93 \mathrm{abc} \\
5,87 \mathrm{c}-\mathrm{j} \\
5,37 \mathrm{a}-\mathrm{f} \\
5,88 \mathrm{c}-\mathrm{j} \\
6,31 \mathrm{e}-\mathrm{j} \\
6,37 \mathrm{~g}-\mathrm{j} \\
6,40 \mathrm{~g}-\mathrm{j} \\
5,54 \mathrm{a}-\mathrm{h}\end{array}$ & $\begin{array}{l}\text { 22. CMT } 011022 \\
\text { 23. CMT } 011034 \\
\text { 24. CMT } 011036 \\
\text { 25. CMT } 011038 \\
\text { 26. CMT } 011040 \\
\text { 27. CMT } 011042 \\
\text { 28. CMT } 011044 \\
\text { 29. CMT } 011046 \\
\text { 30. CMT } 011048 \\
\text { 31. CMT } 011050 \\
\text { 32. CMS } 951220 \text { (RE) } \\
\text { 33. CMT } 011052 \\
\text { 34. CMT } 011054 \\
\text { 35. CMT } 011056 \\
\text { 36. CMT } 011058 \\
\text { 37. CMS } 9510204 \\
\text { 38. CMT } 011060 \\
\text { 39. CMT } 011062 \\
\text { 40. CMS } 971006 \\
\text { 41. Local check-1 } \\
\text { 42. Local check-2 } \\
\text { KK (\%) }\end{array}$ & $\begin{array}{c}5,76 \mathrm{~b}-\mathrm{j} \\
6,12 \mathrm{e}-\mathrm{j} \\
5,81 \mathrm{c}-\mathrm{j} \\
5,47 \mathrm{a}-\mathrm{g} \\
5,61 \mathrm{a}-\mathrm{h} \\
4,82 \mathrm{ab} \\
5,95 \mathrm{e}-\mathrm{j} \\
5,35 \mathrm{a}-\mathrm{e} \\
5,52 \mathrm{a}-\mathrm{h} \\
6,15 \mathrm{e}-\mathrm{j} \\
5,48 \mathrm{a}-\mathrm{g} \\
5,35 \mathrm{a}-\mathrm{e} \\
6,18 \mathrm{e}-\mathrm{j} \\
5,88 \mathrm{c}-\mathrm{j} \\
5,90 \mathrm{c}-\mathrm{j} \\
6,67 \mathrm{j} \\
6,06 \mathrm{e}-\mathrm{j} \\
5,86 \mathrm{c}-\mathrm{j} \\
5,92 \mathrm{~d}-\mathrm{j} \\
6,85 \mathrm{j} \\
6,62 \mathrm{ij} \\
\\
8,30\end{array}$ \\
\hline
\end{tabular}

Keterangan : Angka yang diikuti oleh huruf yang sama tidak berbeda nyata pada taraf $5 \%$

juga disimpulkan agak tahan. Kemudian genotipe ini terserang $E$. lignocellus $0,93 \%$, angka ini terletak diantara $(X)=0,84$ dan $(X+1 S D)=2,55$ sehingga disimpulkan peka, dan selanjutnya genotipe ini agak tahan terhadap Ostrinia $s p$. Jadi reaksi ketahanan genotipe 991002 agak tahan terhadap Spodoptera sp., Mythima sp., dan Ostrinia sp. Tetapi peka terhadap $E$. lignocellus. Tingkat ketahanan varietas terhadap hama tergantung kepada genotipe dan stadia pertumbuhan tanaman, serta perilaku makan serangga hama (Prasadja, 1993).

Terdapat 12 genotipe jagung hibrida introduksi yang menunjukkan reaksi agak tahan terhadap semua jenis hama yang ditemukan. Genotipe-genotipe tersebut adalah CMS 991006 (No. 3), CMT 011004 (No. 4), CMT 011018 (No. 12), CMT 011028 (No. 19), CMT 011030 (No. 20), CMT 011036 (No. 24), CMT 011038 (No. 25), CMT 011044 (No. 28), CMT 011050 (No. 31), CMS 951220 (RE) (No. 32), CMT 011056 (No. 35), CMT
011060 (No. 38). Sedangkan varietas pembanding Pioneer 13 (P 13) agak tahan terhadap Spodoptera sp., mythimna sp. dan E. lignocellus, tetapi peka terhadap Ostrinia $s p$.. Varietas Pioneer memang dilaporkan agak tahan terhadap serangan hama. Hasil penelitian Dewi dkk., (1999) menunjukkan bahwa jagung varietas Pioneer 4 kurang disukai ulat Heliothis $s p$. sedangkan varietas Pioneer 9 kurang disukai oleh hama pengisap Nezara viridula. Kemudian Pioneer 2 dilaporkan tahan terhadap lalat bibit (Subandi dkk., 1998). Genotipe CMS 991018 (No. 13) menunjukkan reaksi peka terhadap semua jenis hama yang ditemukan. Sedangkan genotipe-genotipe lainnya menunjukkan reaksi ketahanan yang beragam terhadap hama yang ditemukan.

Hasil pipilan kering berkisar dari 4,78 - 6,85 tha (Tabel 3). Ada 13 genotipe yang mempunyai hasil tertinggi (di atas $6 \mathrm{t} / \mathrm{ha}$ ) berturut-turut adalah $\mathrm{CMS}$ $9510204($ No. 37$)=6,67$ tha, CMS $991002($ No. 1$)=$ 6,46 tha, CMT011030 (No. 20) $=6,40$ tha, CMT 
011028 (No. 19) $=6,37$ tha, CMT 011002 (No. 2) $=$ 6,33 tha, CMT 011026 (No. 18) $=6,31$ tha, CMT $011054($ No. 34$)=6,18$ tha, CMT011050 (No. 31) $=$ 6,15 tha, CMT 011034 (No. 23) $=6,12$ tha, CMT $011010($ No. 8$)=6,08$ tha, CMT $011060($ No. 38) $=6$, 06 tha, CMS 991018 (No. 13) $=6,05$ tha, CMT 011014 (No. 10) $=6,04$ t/ha. Semua genotipe di atas secara statistik tidak berbeda nyata dengan pembanding Pioneer 13. Empat diantaranya adalah genotipe yang menunjukkan reaksi agak tahan terhadap semua jenis hama yaitu CMT 011030 (No. 20) =6,40 tha, CMT $011028($ No. 19) $=6,37$ tha, CMT $011050($ No. 31) $=$ 6,15 tha dan CMT 011060 (No. 38) $=6,06$ tha. Hasil hibrida pembanding masing-masing Pioneer $13=6,85$ tha dan Andalas = 6,62 ton/ha.

\section{SIMPULAN}

Dari hasil penelitian dapat disimpulkan bahwa terdapat 12 genotipe jagung hibrida yang menunjukkan reaksi agak tahan terhadap semua jenis hama yang ditemukan yaitu CMS 991006, CMT 011004, CMT 011018, CMT 011O28, CMT 011030, CMT 011036, CMT 011038, CMT 011044, CMT 011050 , CMS 951220 (RE), CMT 011056, CMT 011060 dan 1 genotipe menunjukkan reaksi peka terhadap semua jenis hama yang ditemukan yaitu CMS 991018. Sedangkan genotipe jagung hibrida lainnya menunjukkan reaksi ketahanan yang beragam terhadap hama yang ditemukan. Hama-hama yang ditemukan adalah hama perusak daun Spodoptera sp., Mythimna sp., dan Elasmopalpus lignocellus dan penggerek batang Ostrinia $s p$. Genotipe yang mempunyai hasil tinggi dan juga agak tahan terhadap semua hama yang ditemukan adalah CMT011030 = 6,40 tha, CMT $011028=6,37$ t/ha, CMT011050 $=$ 6,15 tha dan CMT $011060=6,06$ tha.

\section{DAFTAR PUSTAKA}

Balai Penelitian Tananaman Serealia. 2002. Inovasi Teknologi Jagung. Badan Litbang. Puslitbangtan. $19 \mathrm{hlm}$.

Chiang \& N.S. Talekar. 1980. Identification of sources of resistance to the beanfly and two Agromizid Flies in soybean and mungbean. J. Econ. Entomol. 73 : 197-199.

Dewi R.M., Hayani, Yulia P., L.Hutagalung \& Dani P. 1999. Preferensi Nezara viridula terhadap Beberapa Varietas Jagung. Hlm.455-460. Prosiding Seminar Nasional Peranan Entomologi dalam Pengendalian Hama yang Ramah Lingkungan dan Ekonomi. Bogor 16 Februari 1999.

Dewi R.M., Hayani, Yulia P., Sudarno \& Dadin S. 1999. Pengaruh Dosis Pupuk dan Varietas Jagung Terhadap Populasi Ulat Heliothis sp. Jurnal Penelitian Sains dan Teknologi. Edisi Khusus Desember 1999: 25-30.

Prasadja, I., Bahagiawati A.H., \& Toto Djuwarso. 1993. Pengendalian Hama Tanaman Pangan Dengan Varietas Tahan. Pemantapan Penelitian Hama Tanaman Pangan. Hlm. 5767. Risalah Lokakarya. Balittan Sukarami, 4-7 Maret 1993.

Subandi, Inu G. Ismail, \& Hermanto. 1988. Jagung. Teknologi Produksi dan Pasca Panen. Puslitbangtan. Badan Litbang Pertanian. $57 \mathrm{hlm}$. 